R. Sutter

C. Arber

A. Tichelli

A.J. Steck

A. Czaplinski

\section{Cranial and peripheral neuropathy due to leptomeningeal infiltration in a patient with Waldenstrom's macroglobulinemia}

Received: 20 April 2006

Received in revised form: 26 August 2006 Accepted: 7 September 2006

Published online: 3 August 2007

Sirs: Lymphoplasmacytic lymphoma or Waldenstrom's macroglobulinemia (WM) is a chronic mature B-cell lymphoproliferative disorder of plasmacytoid lymphocytes usually involving bone marrow, lymph nodes and spleen. A serum monoclonal immunoglobulin M (IgM) may be present and may be associated with hyperviscosity and/ or cryoglobulinemia.

We present the case of a 70 year old male who was diagnosed with WM. Bone marrow infiltration at time of diagnosis was $40 \%$, the monoclonal IgM kappa in peripheral blood was $11.5 \mathrm{~g} / \mathrm{l}$, and cryoglobulines were present. A therapy with four cycles of R-CHOP (rituximab, cyclophosphamid, doxo-

Dr. R. Sutter $(\varangle)$ · A.J. Steck ·

A. Czaplinski

Dept. of Neurology

University of Basel

Patersgraben 4

4031 Basel, Switzerland

E-Mail: sutterr@uhbs.ch

C. Arber · A. Tichelli

Dept. of Hematology, University of Basel, Switzerland rubicin, vincristin, and prednison) was administered. The patient responded well to therapy and achieved a good partial remission with only a residual bone marrow infiltration of $5-10 \%$ and the monoclonal IgM kappa in peripheral blood was $0.7 \mathrm{~g} / \mathrm{l}$.

Six months later the patient gradually developed persistent headaches, nuchal rigidity, double vision, dysphagia and dysarthria. The clinical examination at admission showed meningism and severe bulbar paralysis along with symptoms of sensori-motor polyneuropathy.

Examination of cerebrospinal fluid disclosed 106 cells $/ \mathrm{mm} 3$, elevated protein level $(3160 \mathrm{mg} / \mathrm{l})$ and elevated beta-2-microglobulin $(6.35 \mathrm{mg} / \mathrm{l})$. Cytological analyses revealed atypical lymphocytes and flow cytometry analysis showed a kappa monoclonal CD19 positive B-cell population. Bone marrow examination showed a persistent multifocal infiltration with lymphoplasmacytic lymphoma (15\% of nucleated cells). Transformation in a diffuse large B cell lymphoma was excluded. The serum monoclonal IgM kappa was $0.4 \mathrm{~g} / \mathrm{l}$, cryoglobulines were low, and serum antiMAG (myelin associated glycoprotein) antibodies were negative. The brain MRI showed a mild thickening of leptomeninges without tumor mass or meningeal enhancement. In addition the MRI of the lumbar spinal cord after gadolinium injection showed an increased signal in perimedullary and cauda equina roots regions, as well as enlargement of the latter (Fig. 1 and 2).

We interpreted the symptoms as cranial and peripheral neuropathy due to leptomeningeal and nerve root infiltration and the patient was given a palliative radiation-therapy of the brain and the cauda with simultaneous steroid

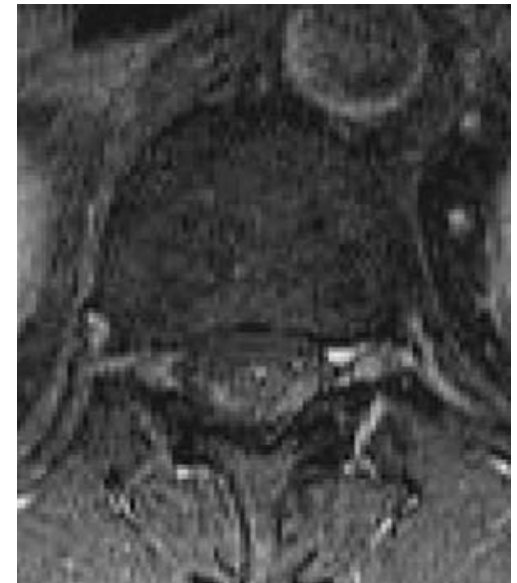

Fig. 1 Axial T1-weighted MRI of lumbar spinal cord after gadolinium showed an increased signal in perimedullary regions

therapy. The patient's condition improved with a clear decrease of bulbar and polyneuropathic symptoms. Although these therapeutic interventions were established, the patient died eleven weeks after diagnosis.

Sensori-motor neuropathy related to the antibody activity of the monoclonal IgM to the MAG is a well-known neurological complication of WM $[2,3]$. However, involvement of the peripheral nervous system due to leptomeningeal infiltration by neoplastic cells is very rare and has been reported in few cases only [1, 4-6]. Remarkably, in contrast to other non-Hodgkin's lymphomas where meningeal involvement develops in the setting of progressive disease, in our patient meningeal infiltration occurred in a stable partial remission phase of the WM.

In conclusion, we hypothesize that WM may progress in the nervous system without transformation into a more malignant Bcell-lymphoma (Richter syndrome) even if the initial chemotherapy leads to significant remission of the disease. 
Fig. 2 Sagittal T1-weighted MRI of lumbar spinal cord after gadolinium showed an increased signal in perimedullary and cauda equina roots regions
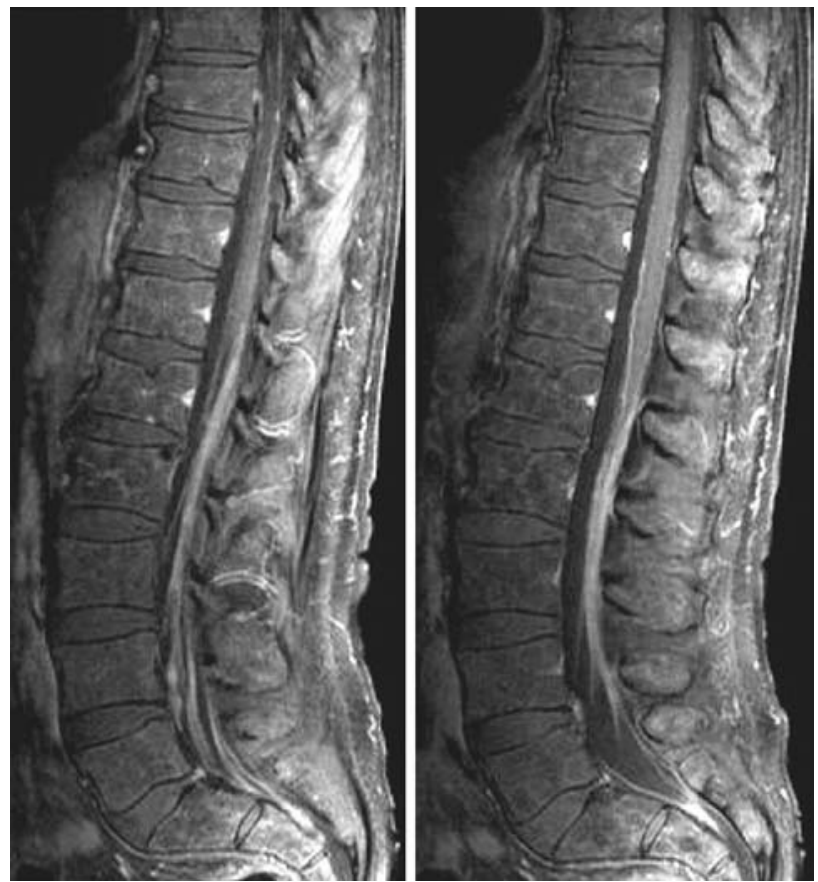

\section{References}

1. Abad S, Zagdanski A-M, Brechignac S, Thioliere B, Brouet JC, Mariette X (1999) Neurolymphomatosis in Waldenström's macroglobulinaemie. $\mathrm{Br}$ J Haematol 106: 100-103

2. Braun PE, Frail DE, Latov N (1982) Myelin-associated glycoprotein ist the antigen for a monoclonal IgM in polyneuropathy. J Neurochem 39: 1261-1265
3. Dellagi K, Dupouey P, Brouet JC, Billecocq A, Gomez D, Clauvel JP, Seligmann M (1983) M. Waldenstrom's macroglobulinemia and peripheral neuropathy: a clinical study of 25 patients. Blood 62: $280-285$

4. Hug A, Haas J, Storch-Hagenlocher B, Wildemann B (2004) Leptomeningeale Tumorzellinfiltration als Erstmanifestation eines Immunozytoms (M. Waldenström). Nervenarzt 75: 1012-1015
5. Massengo S, Riffaud L, Morandi X, Bernard M, Verin M (2003) Nervous system lymphoid infiltration in Waldenström's macroglobulinemia. A case report. J Neuro-Oncol 62: 353-358

6. Noel J, Gille M, Garbar Ch, Martens M, Verhulst D, Vandeput Y (2002) Primary central nervous system lymphoma with Waldenström's macroglobulinaemia. Eur Neurol 47: 184-185 